\title{
EDITORIAL
}

\section{Physiotherapy in bronchiectasis: we have more patients, we need more evidence}

\author{
M.Á. Martínez-García* and J.B. Soriano*,
}

5 eyond any reasonable doubt, one of the greatest achievements of medicine in the last century has been the successful reduction of morbidity and mortality due to infectious disease. In 1938, a landmark paper in the Edinburgh Medical Journal by COOKSON and MASON [1] highlighted the high lethality of bronchiectasis even before the fourth decade of life $[1,2]$. Thanks to improved hygiene measures and antibiotic treatment, what used to be a fatal disease has now become a chronic disease. The major, scattered lung lesions due to cystic bronchiectasis and often associated with outbreaks of infectious diseases, have given way to smaller, cylindrical bronchiectasis as a consequence of dozens of diseases being able to generate lung damage [3]. However, far from being an extinct disease, bronchiectasis has emerged with force. The ever increasing lifespan of humans, with more people at risk of developing chronic illnesses with potential to bronchiectasis, and the widespread use of imaging techniques (such as chest high-resolution computed tomography), have increased the burden, particularly in the elderly [4, 5]. But the relevance of bronchiectasis goes beyond its mere presence, as bronchiectasis worsens the prognosis of the generating disease [6] and is associated with an accelerated loss of lung function [7], increased mortality [8] and a significant reduction in quality of life $[9,10]$.

Notwithstanding the sufferers' individual implications and new epidemiological situation, bronchiectasis still attracts little interest. In 1988, BARKER and BARDANA [11] described bronchiectasis as an "orphan disease" of the airways. However, to date, there is no or little evidence for the effectiveness of most of their treatments, including anticholinergic therapy, inhaled or oral corticosteroids, inhaled hyperosmolar agents, leukotriene receptor antagonists, short- and long-acting $\beta_{2}$-agonists, methyl-xanthines, mucolytics, and even bronchopulmonary hygiene physical therapy [12]. All these treatments are actually used by extrapolation from success in other diseases with airflow obstruction. However, caution must be exercised as this is not always appropriate and might even be harmful to patients [13]. Therefore, studies with an appropriate level of evidence in bronchiectasis are welcome.

\footnotetext{
*Pneumology Unit, General Hospital of Requena, Valencia, ${ }^{\text {\#Program of Epidemiology and Clinica }}$ Research, Fundación Caubet-CIMERA, and "CIBER de enfermedades respiratorias, Illes Balears, Bunyola, Spain.

CORRESPONDENCE: M.Á. Martínez-García, Pneumology Unit, General Hospital of Requena, Valencia, Spain. E-mail: miangel@comv.es
}

The increase in quantity and purulence of sputum viscosity, with retention of broncho-pulmonary secretions characteristic of bronchiectasis, leads to functional airflow obstruction, atelectasis and an increased risk of chronic colonisation of the bronchial mucosa by potentially pathogenic microorganisms, which clouds patients' prognosis [14, 15]. While enrolment in a regular program of chest physiotherapy is considered standard in patients with non-cystic fibrosis bronchiectasis [16, 17], a secular unavailability of scientific evidence of physiotherapy still occurs, and there are no studies of adequate methodology to support efficacy and effectiveness. A handful of studies, most of short-term duration and diverse methodologies, have reported improvements in airway clearance and other clinical parameters associated with physiotherapy in bronchiectasis $[18,19]$.

In the current issue of the European Respiratory Journal, MURRAY et al. [20] present a randomised controlled trial (RCT) on the effectiveness of regular chest physiotherapy on clinical, functional and microbiological outcomes, as well as quality of life. In a crossover trial design, 20 patients with clinically active bronchiectasis underwent treatment for 3 months with two daily sessions of chest physiotherapy by an oscillatory positive expiratory pressure device (the control group was not subjected to this treatment). They report improvements in the Leicester Cough Questionnaire score, a questionnaire developed and validated to determine the impact of cough severity on quality of life, and also an increase in the capacity for expectoration, exercise capacity, and an improvement in quality of life assessed by the St. George's Respiratory Questionnaire [20]. No significant adverse effects occurred during the trial duration, although there were no changes in lung function, microbiology or number of exacerbations. The study by MURRAY et al. [20] has some obvious limitations, mainly related to its reduced sample size, including the statistical versus clinical significance of some reported changes, and the lack of a placebo or sham group by study design, which the authors recognise. However, it should be considered a step forward for the following reasons: 1) it is the first study that provides valuable information with clinical trial methodology on the effectiveness of regular respiratory physiotherapy for these patients; and 2) it helps to re-open the debate about the critical need for long-term multicenter trials in bronchiectasis, with larger sample sizes and a methodology that ensures a higher level of evidence in these patients. These studies should serve not only to answer the seminal question of whether regular chest physiotherapy is effective or not, but to address other key questions that remain unsolved yet, such 
as: What is the most effective technique?, How many times a day and for how long should chest physiotherapy programs be used for?, What is the effectiveness of chest physiotherapy treatments combined with antibiotics, bronchodilators and/or muscle training?, What is the effectiveness of physiotherapy long-term and what are the related effects on lung function decline or exacerbations?, Are there subpopulations of patients with bronchiectasis who might benefit the most from treatment?, and Is treatment cost-effective?, among other issues. While waiting for these studies, we will continue living in the realm of expert opinion. M.C. Sosman, a reputed radiologist from Boston (MA, USA) lectured to his students that "... we see only what we look for, and we recognize only what we know" [21]. Perhaps, a necessary first step should be for clinicians to suspect a diagnosis of bronchiectasis, a disease of growing importance, and to consider that, in a patient with obstructive airways, not always and not only chronic obstructive pulmonary disease or asthma are to blame for the bronchial damage. Twenty years after the state-of-the-art study by BARKER and BARDANA [11], bronchiectasis remains an "orphan disease" of the airways.

\section{STATEMENT OF INTEREST}

None declared.

\section{REFERENCES}

1 Cookson HA, Mason GA. Bronchiectasis - a fatal disease. Edinb Med J 1938; 45: 844-854.

2 Perry KMA, King DS. Bronchiectasis, a study of prognosis based on a follow-up of 400 patients. Am Rev Tuberc 1940; 41: 531-548.

3 Martínez-García MA. Bronquiectasias: Aún una enfermedad huérfana? [Bronchiectasis: still an orphan disease?]. Arch Bronconeumol 2005; 41: 407-409.

4 Nicotra MB, Rivera M, Dale AM, et al. Clinical, pathophysiologic, and microbiologic characterization of bronchiectasis in an aging cohort. Chest 1995; 108: 955-961.

5 Naidich DP, McCauley DI, Khouri NF, et al. Computed tomography of bronchiectasis. J Comput Assist Tomogr 1982; 6: 437-444.
6 Swinson DR, Symmons D, Suresh V, et al. Decreased survival in patients with co-existent rheumatoid arthritis and bronchiectasis. Br J Rheumatol 1997; 36: 689-691.

7 Martínez-García MA, Perpiñá-Tordera M, Román-Sánchez P, et al. Factors associated with lung function decline in patients with noncystic fibrosis bronchiectasis. Chest 2007; 132: 1565-1572.

8 Keistinen T, Säynäjäkangas O, Tuuponen T, et al. Bronchiectasis an orphan disease with a poorly-understood prognosis. Eur Respir J 1997; 10: 2784-2787.

9 Martínez-García MA, Perpiñá M, Román P, et al. Quality of life determinants in patients with clinically stable bronchiectasis. Chest 2005; 128: 739-745.

10 Wilson CB, Jones PW, O'Leary J, et al. Validation of the St George's Respiratory Questionnaire in bronchiectasis. Am J Respir Crit Care Med 1997; 156: 536-541.

11 Barker AF, Bardana EJ. Bronchiectasis: update of an orphan disease. Am Rev Respir Dis 1988; 137: 969-978.

12 ten Hacken NHT, Wijkstra PJ, Kerstjens HAM. Treatment of bronchiectasis in adults. Br Med J 2007; 335: 1089-1093.

13 O'Donnell AE, Barker AF, Ilowite JS, et al. Treatment of idiophatic bronchiectasis with aerosolized recombinant human DNAse I. Chest 1998; 113: 1329-1334.

14 O'Donnell AE. Bronchiectasis. Chest 2008; 134: 815-823.

15 Bilton D. Update on non-cystic fibrosis bronchiectasis. Curr Opin Pulm Med 2008; 14: 595-599.

16 Vendrell M, de Gracia J, Olveira C, et al. [Diagnosis and treatment of bronchiectasis. Spanish Society of Pneumology and Thoracic Surgery]. Arch Bronconeumol 2008; 44: 629-640.

17 Woodhead M, Blasi F, Ewing S, et al. Guidelines for the management of adult lower respiratory tract infections. Eur Respir J 2005; 26: 1138-1180.

18 Garrod R, Lasserson T. Role of physiotherapy in the management of chronic lung diseases: an overview of systematic reviews. Respir Med 2007; 101: 2429-2436.

19 McCool FD, Rosen MJ. Nonpharmacologic airway clearance therapies: ACCP evidence-based clinical practice guidelines. Chest 2006; 129: Suppl. 1, 250S-259S.

20 Murray MP, Pentland JL, Hill AT. A randomised crossover trial of chest physiotherapy in non-cystic fibrosis bronhiectasis. Eur Respir J 2009; 34; 1086-1092.

21 Sosman MN, Dodd GD, Jones WD, et al. The familial occurrence of pulmonary alveolar microlithasis. Am J Roentgenol Radium Ther Nucl Med 1957; 77: 947-1012. 